\title{
Perioperative Pulmonary Support of the Elderly
}

\author{
Catherine Entriken ${ }^{1} \cdot$ Timothy A. Pritts ${ }^{1}$ (I)
}

Accepted: 22 August 2021 / Published online: 9 November 2021

(c) The Author(s), under exclusive licence to Springer Science+Business Media, LLC, part of Springer Nature 2021

\begin{abstract}
Purpose of Review With the projected increase in the geriatric patient population, it is of the utmost importance to understand and optimize conditions in the perioperative period to ensure the best surgical outcome. Age-associated changes in respiratory physiology affect the surgical management of geriatric patients. This review focuses on perioperative pulmonary management of elderly individuals.

Recent Findings The physiological changes associated with aging include both physical and biochemical alterations that are detrimental to pulmonary function. There is an increased prevalence of chronic lung disease such as COPD and interstitial lung disease which can predispose patients to postoperative pulmonary complications. Additionally, elderly patients, especially those with chronic lung disease, are at risk for frailty. Screening tools have been developed to evaluate risk and aid in the judicious selection of patients for surgical procedures. The concept of "prehabilitation" has been developed to best prepare patients for surgery and may be more influential in the reduction of postoperative pulmonary complications than postoperative rehabilitation. Understanding the age-associated changes in metabolism of drugs has led to dose adjustments in the intraoperative and postoperative periods, reducing respiratory depression and lung protective ventilation and minimally invasive procedures have yielded reductions in postoperative pulmonary complications.

Summary The perioperative management of the geriatric population can be divided into three key areas: preoperative risk mitigation, intraoperative considerations, and postoperative management. Preoperative considerations include patient selection and thorough history and physical, along with smoking cessation and prehabilitation in a subset of patients. Operative aspects include careful selection of anesthetic agents, lung protective ventilation, and choice of surgical procedure. Postoperative management should focus on selective use of agents that may contribute to respiratory depression and encouragement of rehabilitation.
\end{abstract}

Keywords Perioperative management · Pulmonary support · Geriatric surgery

\section{Introduction}

The world's population of individuals over 60 years old is expected to increase to 2 billion people by 2050 [1], and in the

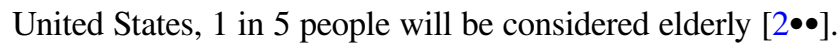
With the projected increase in the geriatric population, the medical community must learn to understand how to care for patients in this demographic group. It is important to tailor

This article is part of the Topical Collection on Pulmonology and Respiratory Care

Timothy A. Pritts

prittsta@ucmail.uc.edu

Catherine Entriken

centriken@gmail.com

1 Section of General Surgery, Department of Surgery, University of Cincinnati, Cincinnati, OH, USA treatment plans to address the nuances of medical care required of this cohort. With the growing geriatric population, there is an increasing number of elderly presenting for surgical care. It is imperative to understand and optimize conditions not only during surgical procedures, but in the pre- and post-operative periods. This review will focus on perioperative pulmonary support in the geriatric population. The changes in respiratory physiology due to age will be reviewed along with additional risk factors applicable to the geriatric population. Information will then be presented on pre-operative risk mitigation, operative considerations, and finally post-operative management (Fig. 1).

\section{Respiratory Physiology in the Elderly and Risk Factors for Disease}

There is a decrease in pulmonary function as an individual ages, with studies showing a $40 \%$ decline in overall function between the ages of 25-80 [1]. These changes are driven by 


\section{PREOPERATIVE RISK MITIGATION}

- Screening

- History and Physical

- Patient selection

- Smoking cessation

- Prehabilitation

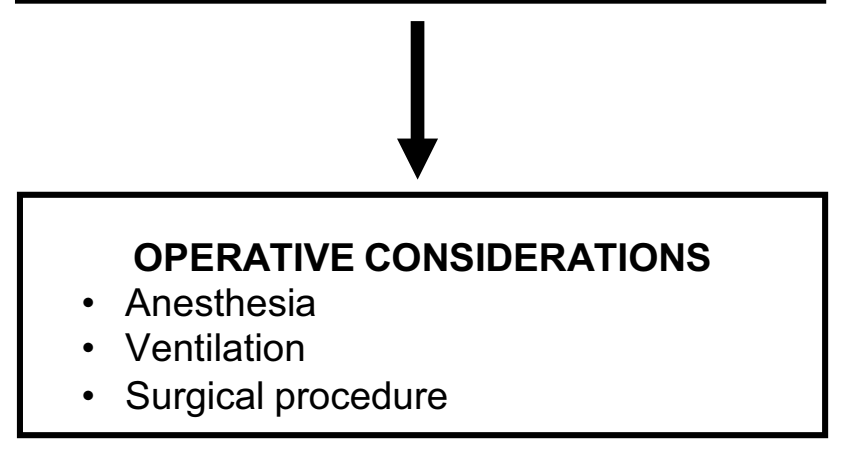

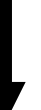

\section{POSTOPERATIVE MANAGEMENT}

- Pain control, choice of analgesic

- Rehabilitation

Fig. 1 The three key aspects of perioperative pulmonary support

both physical and biochemical factors. Overall changes in the structure of the body contribute to reduced lung expansion including loss of vertebral body height, decreased chest wall compliance, and loss of muscle mass. On a molecular level, alterations in collagen associated with age lead to alveolar duct dilation and loss of lung recoil. With these physical changes, there is a decrease in tidal volume, FEV1, and FVC, and increases in residual volume and respiratory rate $[1,3]$. The vasculature of the pulmonary system is also affected with increases in pulmonary arterial pressure resulting in an increased A-a gradient [4]. Oxidative metabolism is reduced along with expiration of $\mathrm{CO} 2$. The aging pulmonary system has a decreased responsiveness to chemoreceptors causing a weakened response to hypoxia or hypercapnia [5].

\section{Obstructive and Restrictive Lung Disease}

The effect of aging on a biochemical level has been the subject of much research. Possible deleterious mechanisms include mitochondrial dysfunction and telomere shortening. It is postulated that the rising number of primary senescent cells reduce capacity for tissue repair and increase numbers of pro-inflammatory molecules [5]. The accumulation of senescent cells has been implicated in the development of diseases such as COPD demonstrating a mechanism of "accelerated aging" [6,7]. It is important to note the increasing prevalence of COPD in the geriatric population with the disease occurring in 1,200 in 10,000 people over the age of 65 as compared to 200 in 10,000 patients under 45 years of age [8]. Smoking is a known risk factor for development of the disease but up to one third of COPD cases occur in nonsmokers [7]. Furthermore, the presence of the disease has significant implications in surgical treatment. A European study of 1,842 elderly patients with aortic stenosis examined the impact of COPD in patients undergoing variable approaches for aortic valve implantation. Patients with COPD undergoing transapical aortic valve implantation were found to have higher rates of postoperative pneumonia compared to those without COPD. Additionally, patients with COPD displayed reduced long-term survival compared to patients without COPD [9].

The incidence of interstitial lung disease (ILD) also increases with age. Idiopathic pulmonary fibrosis (IPF) is a well-known type of ILD marked by interstitial inflammation with permanent and progressive scarring of pulmonary tissues [10]. The majority of IPF patients are males over the age of 60, and again, a history of smoking is often seen [11]. Acute exacerbations of IPF are associated with poor prognosis and have been seen following surgical procedures on the lungs to include biopsies, lobectomies, and bronchoalveolar lavage. The mechanisms are unclear, necessitating judicious selection of these patients for procedures [12]. There has also been focus on improving the baseline performance capabilities of these patients with exercise training programs. An Australian study randomized ILD patients into 2 groups, one group receiving usual care and the other enrolled in an 8-week supervised exercise training program. It was found that six-minute walk distance scores and quality of life survey scores were improved in the exercise group. They did note, however, that prolonged treatment effects were associated with milder disease at baseline [10].

Obstructive sleep apnea (OSA) is characterized by cyclical obstruction of the respiratory tract during periods of sleep. This disease process can lead to detrimental changes within the cardiovascular and pulmonary systems, increasing risk for atherosclerosis and hypertension [13] and there is an association between OSA and postoperative complications [14]. OSA prevalence is as high as $38 \%$ in the general population, is more common in men, and is associated with obesity [15]. However, in men aged 60-85 years, the prevalence of OSA has been shown to be as high as 43-90\% [15, 16]. Given the high number of individuals affected, it is important to screen patients using validated tools. Examples of such are the STOP-Bang questionnaire (SBQ), Berlin questionnaire, 
STOP questionnaire, and Epworth sleepiness scale. The SBQ was developed in 2008 and is comprised of 8 items: snoring, tiredness, observed apnea, high blood pressure, BMI, age, neck circumference, and gender (Table 1). The questionnaire has demonstrated high sensitivity in detecting OSA in various patient populations [17]. A 2016 meta-analysis suggested the SBQ to be highly sensitive compared to alternative tools [18]. If a patient is suspected of having OSA, polysomnography (PSG) is considered the gold standard for diagnosis and should be performed as several PSG parameters may be able to more accurately predict postoperative adverse events [16]. Pre-operative diagnosis of OSA may allow intervention, including initiation of CPAP therapy.

\section{Frailty}

Although aging is an inescapable aspect of human existence, the geriatric population should not be viewed through a singular lens and individual physiologic status should be considered. There has been a movement to focus more closely on the concept of "frailty" defined by a decrease in physiologic reserve and increased vulnerability to stress [19]. While frailty does increase with age, it is not necessarily equivalent to aging.

Multiple screening tools have emerged over the years including, but not limited to, the clinical frailty scale (CFS), the Fatigue, Resistance, Ambulation, Illnesses, and Loss of Weight (FRAIL) scale, the Fried frailty phenotype, the PRISMA questionnaire, and the timed up-and-go test [20]. A systematic review found that in both elective and acute operations, frailty in patients over 75 years of age is strongly associated with 30 day mortality [21].

A study of 326 general surgery patients found a higher rate of in-hospital complications, and in particular, a significantly higher rate of respiratory complications [22••]. In addition, frailty is closely associated with COPD and IPF. A 2018 meta-analysis concluded that elderly individuals with COPD have a two-fold increased risk of frailty [23]. Another study assessed IPF patients aged 65 years or older with the Fried frailty phenotype (weight loss, weakness, slowness, low level of physical activity, and exhaustion) and reported $48 \%$ were found to be frail [24].

\section{COVID-19}

The elderly population is more susceptible to respiratory infections at baseline given diminished immune responses. This has been seen in the context of viral infections such as influenza and RSV [25], and most recently, with the emergence of COVID-19. The presence of interstitial lung disease and COVID-19 infection appears to be synergistic in severity and recent study results have found a higher mortality rates in elderly males with IPF [26].

The COVID-19 pandemic has also sparked questions as to the effects of infection in the perioperative period especially within the geriatric population, a cohort at greater risk of acquiring the infection and increased severity. An international, multicenter study examining surgical patients with a perioperative COVID diagnosis within 7 days before or 30 days after surgery found that half of patients positive for the disease experienced postoperative pulmonary complications. Additionally, 30-day mortality was associated with males aged 70 years or older [27]. Another recent study also found an increase in 30-day mortality due to postoperative respiratory pathology in COVID positive surgical patients with all patients in that cohort over the age of 65 . Generally, it is currently recommended to defer all non-urgent, and elective surgery especially among elderly males during the pandemic [28].

\section{Preoperative Risk Mitigation}

The importance of preoperative assessment cannot be overstated and should include a thorough discussion of the patient's health history to include presence of comorbidities, environmental risk factors such as history of smoking and occupational exposures and a physical exam.
Table 1 The STOP-BANG Questionnaire screening tool for obstructive sleep apnea (OSA). A score of $0-3$ is associated with a low risk of OSA, 4-5 with an intermediate risk for OSA, and 6-8 with a high risk for OSA (http://www.stopbang. ca/osa/screening.php)

\begin{tabular}{ll}
\hline ITEM & METRIC \\
\hline Snoring & Loud snoring which can be heard through closed doors \\
Tiredness & Daytime fatigue \\
Observation & Has someone observed gasping or cessation of breath- \\
& ing during sleep? \\
High Blood Pressure & Are you treated for high blood pressure? \\
BMI & Over $35 \mathrm{~kg} / \mathrm{m}^{2}$ \\
Age & Over 50 \\
Neck circumference & - Greater than 17 inches for males \\
Gender & - Greater than 16 inches for females \\
\hline
\end{tabular}




\section{Screening and Pulmonary Function Testing}

Comorbid conditions such as OSA and frailty may increase the risk of postoperative complications. Routine use of these screening instruments to detect these diseases is widely recommended. Additionally, the Assess Respiratory Risk in Surgical Patients in Catalonia (ARISCAT) risk index is an externally validated tool used to assist in predicting postoperative pulmonary complications and is composed of seven criteria: age, preoperative oxygen saturation, respiratory infection in the last month, preoperative anemia, upper abdominal or intrathoracic surgical incision, duration of surgery, and emergent procedure [29].

Aside from its preoperative use in thoracic surgery, pulmonary function testing (PFT) prior to non-thoracic surgery is not typically recommended, although the debate over its merits continues [30]. A study examining patients undergoing either open or laparoscopic elective abdominal surgery who had received preoperative PFT found that while vital capacity was an independent predictor of postoperative pulmonary complications, a model using age, duration of surgery, and blood transfusion was not inferior [31]. Another recent study examined patients undergoing laparoscopic gastric or colorectal cancer surgery who had PFT within one month of surgery for either age over 60 years, current smoking, or history of chronic pulmonary disease. After multivariable logistic regression, it was found that a lower FVC was significantly associated with postoperative pulmonary complications. Also significant were age, surgery duration, and blood transfusion [32]. In addition to the question over its preoperative predictive value, the quality of spirometry has been questioned in advanced age, especially in association with reduced cognition. A study examining spirometry results in elderly individuals found that age over 78 years and a Mini-Mental State Examination cutoff score of 15 points was significantly associated with poor quality spirometric results [33].

\section{Smoking Cessation}

The serious negative health consequences attributed to smoking are well established. According to a 2019 CDC report, $8.2 \%$ of adults 65 years and older are current cigarette smokers [34]. There are a variety of options available to assist older individuals in tobacco cessation including counseling and pharmacotherapy. Pharmacological modalities include nicotine replacement therapy, bupropion, and varenicline. Nicotine replacement therapy has been shown to be effective in older populations [35].

\section{Prehabilitation}

Many surgical procedures performed on the geriatric population are either emergent or urgent resulting in little to no time for physiologic optimization. However, in the context of elective surgery, the concept of "prehabilitation" has been developed. These programs often include fitness and nutritional regimens in order to best prepare an individual for the physiologic stressors of a procedure [36]. In a study examining abdominal surgery patients 70 years or older, it was found that the incidence of postoperative delirium was significantly lower in patients who had undergone a prehabilitation program despite the presence of a higher number of comorbidities [36]. A meta-analysis examining the effect of inspiratory muscle training (IMT) on the presence of postoperative pulmonary complications and length of hospital stay found preoperative physiotherapy to be beneficial in both over a range of ages [37]. Another meta-analysis focusing on patients undergoing cardiothoracic and upper abdominal surgery found a significant reduction in postoperative pulmonary complications when preoperative IMT was instituted, specifically noting the benefit of IMT for $15 \mathrm{~min}$ or more per day for greater than 2 weeks [38].

\section{Operative Considerations}

A review of operative considerations can be found in Table 2.

\section{Anesthesia}

A recent retrospective review of 747 anesthesia cases demonstrated anesthesia-related adverse events in the postoperative period occur more commonly in patients 65 and older compared to those under 65 (37.7\% vs $21.9 \%, \mathrm{p}=.001)$ [39]. Changes in the body composition of aging patients include decreased total body water and a relative increase in body fat. These alterations can cause an increase in the plasma concentrations of hydrophilic drugs and a longer time to onset and longer duration of action of lipophilic drugs [40]. Additionally, renal and hepatic function typically declines in advancing age which can have an effect on metabolism and clearance of drugs [41]. An awareness of these concepts is important in the administration of sedatives, neuromuscular blockade, and analgesic medications. For example, propofol administration tends to cause a greater response and the adverse cardiovascular effects tend to occur later [41]. Benzodiapine clearance is typically reduced and may cause oversedation and respiratory depression [42]. Short-acting opioids such as remifentanil may be of benefit but it must still be noted that dose adjustments are needed to prevent 
Table 2 Operative considerations in pulmonary management

\begin{tabular}{ll}
\hline CONSIDERATION & RECOMMENDATION \\
\hline Anesthesia & - Dose adjustments for drugs given for sedation, neuromuscu- \\
& lar blockade, and analgesia \\
& Reversal of neuromuscular blockade to train-of-four \\
& ratio $>0.9$ after surgical intervention \\
& - Judicious use of general anesthesia and prioritization of \\
& regional anesthesia when possible \\
Ventilation & Low tidal volume ventilation (6-8 ml/kg ideal body weight) \\
& - Individualized PEEP \\
& - Elevation of head of bed prior to induction of anesthesia \\
Surgical procedure & - Use of minimally invasive technique if possible
\end{tabular}

respiratory depression in the elderly patient [42]. Concerning neuromuscular blockade, it is recommended to facilitate complete recovery to a train-of-four ratio $>0.9$ at the end of intervention to avoid complications such as aspirationinduced pneumonia secondary to pharyngeal dysfunction. Sugammadex is recommended for reversal if necessary [43].

Due to the potential risks of general anesthesia, there has been debate over whether regional anesthesia may confer less risk. In a retrospective study of over 16,000 geriatric patients surgically treated for hip fractures, general anesthesia, when compared with regional anesthesia, was found to be associated with a higher risk of mortality during the in-hospital stay. However, there was no significant difference in presence of DVT/PE, myocardial infarction, or pneumonia when comparing the two types of anesthesia [44]. A recent study utilizing the NSQIP database examined over 87,000 patients undergoing inguinal hernia surgery and found a significantly lower rate of postoperative complications in patients 75 years of age and older who were operated on with local anesthesia [45]. The effect of anesthesia type may be even more pronounced in those with comorbid lung disease. A NSQIP database review of COPD patients undergoing surgery found that patients who underwent general anesthesia had higher rates of pneumonia, prolonged ventilator dependence, and unplanned postoperative intubation compared to those who received regional anesthesia [46]. Thus, regional anesthesia should be considered whenever possible.

\section{Ventilation}

Lung protective ventilation to prevent further pulmonary injury is a mainstay of treatment of acute respiratory distress syndrome (ARDS) and its use has also shifted to the perioperative setting. In a systematic review and expert panel, it was determined that low tidal volume ventilation with $6-8 \mathrm{ml} / \mathrm{kg}$ of ideal body weight may be preventive against postoperative pulmonary complications. Additionally, PEEP should be individualized and adjusted as needed. Other recommendations included elevation of the head of bead prior to induction of anesthesia and use of airway adjuncts to avoid upper airway collapse [47].
Studies have been unable to provide high quality evidence for the use of prophylactic continuous positive airway pressure (CPAP) in the immediate postoperative to prevent postoperative pulmonary complications [48].

\section{Surgical Procedure}

The type and nature of the surgical procedure is a predictive factor for pulmonary complication risk. An increased risk for postoperative respiratory failure has been demonstrated in thoracic and upper abdominal procedures as well as in emergent surgery [49].

As surgical technology continues to advance, there has been a focus on advancing minimally invasive procedures. Abdominal laparoscopic surgery requires the creation of pneumoperitoneum in order to create a space to work within. Pneumoperitoneum has known effects on hemodynamics and ventilation, and with the physiological changes seen in elderly adults, it has been the subject of research to determine if elderly patients can tolerate the stress and if it contributes to postoperative complications [50]. A multicenter study examined 1,473 patients undergoing surgery for colorectal cancer and found significantly lower rates of postoperative pneumonia in laparoscopic vs open surgical groups. Additionally, the findings were also true in patients with obstructive and restrictive lung disease [51]. Another systematic review examined over 66,000 patient aged 65 years or older who underwent either open or laparoscopic colorectal surgery and found a significantly lower mortality and a lower rate of pulmonary and cardiac complications in the laparoscopic group [52].

\section{Postoperative Management}

In the postoperative period, patients should be monitored closely, early mobilization is encouraged, and typical aspiration precautions should be observed including elevation of the head of the bed, advanced swallow evaluations when 
appropriate, and remaining upright during and for a period after meals [4]. Evaluation of oxygen saturation and respiratory rate should be performed at intervals with a low threshold for arterial blood gas analysis if conditions warrant [43].

\section{Postoperative Pain Control}

Judicious selection of analgesic medications is necessary to avoid respiratory depression in the postoperative period. Having said that, undertreatment of pain in elderly individuals has been reported in the literature and care must be taken to carefully evaluate the patient's condition [53]. Opioids should be administered in lower doses along with non-narcotic medications such as acetaminophen. NSAIDs should be used with caution given possible gastric or renal effects [43].

With the enhanced recovery after surgery (ERAS) pathway, there has been a focus of multimodal pain control, a concept that can be applied to the elderly population [54]. Transversus abdominis plane (TAP) blocks have been proposed as an adjunct to pain control in older individuals. This procedure involves placement of local anesthetic into the neurovascular plane between the internal oblique and transversus abdominis. In a study of colorectal surgery patients, TAP blocks were found to be non-inferior to pain control when compared to epidural analgesia [55].

\section{Postoperative Pulmonary Rehabilitation}

A 2018 study examining a novel inpatient pulmonary rehabilitation program found that when techniques such as incentive spirometry, chest percussion, and forced expiratory techniques are implemented early, significantly lower rates of pneumonia were observed [56]. Additionally, chest physiotherapy regimens have been noted to reduce secretion accumulation and respiratory muscle atrophy, and improving rapid shallow breathing index scores in ventilated patients [57].

In a randomized control trial, the effects of two weeks of postoperative inspiratory muscle training (IMT) after pulmonary resection in high risk patients were examined. There was no effect on respiratory muscle strength but oxygenation was significantly improved when compared with usual care. Cases of pneumonia were lower in the IMT group but not significantly so (6\% in the control group vs. $21 \%$ in the IMT group, p-value 0.14) [58].

Taking a preventive approach to combat pulmonary complications in the postoperative period may lessen rates of such complications as the aforementioned studies indicate. However, a recent meta-analysis demonstrated unclear benefits of physiotherapy in the postoperative period in preventing postoperative pulmonary complications and it appears that the focus should still lie on the benefit of preoperative physiotherapy when feasible [59].

\section{Conclusions}

There are a growing number of geriatric patients who need surgical care. Recognizing the physiologic changes that occur with advancing age is important in preparing the patient to achieve the most optimal surgical outcome. Preoperative considerations include patient selection, thorough history and physical, along with smoking cessation and prehabilitation in a subset of patients. Operative aspects include careful selection of anesthetic agents, lung protective ventilation, and choice of surgical procedure. Postoperative management should focus on judicious use of agents that may contribute to respiratory depression and emphasize rehabilitation.

\section{Compliance with Ethical Standards}

Conflict of Interest Statement The authors have no conflicts of interest regarding the material presented.

Human and Animal Rights This article does not contain any studies with human or animal subjects performed by any of the authors.

\section{References}

Papers of particular interest, published recently, have been highlighted as:

$\bullet$ Of major importance

1. Roman MA, Rossiter HB, Casaburi R. Exercise, ageing and the lung. Eur Respir J. 2016;48(5):1471-86. https://doi.org/10.1183/ 13993003.00347-2016.

2.• Hanna K, Ditillo M, Joseph B. The role of frailty and prehabilitation in surgery. Curr Opin Crit Care. 2019;25(6):717-722. https://doi.org/10.1097/MCC.0000000000000669. Excellent review of the concept of frailty in surgical patients. Good summary of frailty as a risk factor as well as the concept of pre-habilitation prior to surgery.

3. Chester JG, Rudolph JL. Vital signs in older patients: age-related changes. J Am Med Dir Assoc. 2011;12(5):337-43. https://doi. org/10.1016/j.jamda.2010.04.009.

4. Chow WB, Rosenthal RA, Merkow RP, et al. Optimal preoperative assessment of the geriatric surgical patient: a best practices guideline from the American College of Surgeons National Surgical Quality Improvement Program and the American Geriatrics Society. J Am Coll Surg. 2012;215(4):453-66. https://doi.org/ 10.1016/j.jamcollsurg.2012.06.017.

5. Cho SJ, Stout-Delgado HW. Aging and Lung Disease. Annu Rev Physiol. 2020;82:433-59. https://doi.org/10.1146/annurev-physi ol-021119-034610.

6. Yanagi S, Tsubouchi H, Miura A, Matsuo A, Matsumoto N, Nakazato M. The Impacts of Cellular Senescence in Elderly Pneumonia and in Age-Related Lung Diseases That Increase the Risk of Respiratory Infections. Int J Mol Sci. 2017;18(3):503. Published 2017 Feb 25. https://doi.org/10.3390/ijms18030503.

7. Cortopassi F, Gurung P, Pinto-Plata V. Chronic Obstructive Pulmonary Disease in Elderly Patients. Clin Geriatr Med. 2017;33(4):539-52. https://doi.org/10.1016/j.cger.2017.06.006. 
8. Ascher K, Elliot SJ, Rubio GA, Glassberg MK. Lung Diseases of the Elderly: Cellular Mechanisms. Clin Geriatr Med. 2017;33(4):473-90. https://doi.org/10.1016/j.cger.2017.07.001.

9. Mach M, Koschutnik M, Wilbring M, et al. Impact of COPD on Outcome in Patients Undergoing Transfemoral versus Transapical TAVI. Thorac Cardiovasc Surg. 2019;67(4):251-6. https:// doi.org/10.1055/s-0039-1685177.

10. Dowman LM, McDonald CF, Hill CJ, et al. The evidence of benefits of exercise training in interstitial lung disease: a randomised controlled trial. Thorax. 2017;72(7):610-9. https://doi.org/10. 1136/thoraxjnl-2016-208638.

11. Kishaba T. Acute Exacerbation of Idiopathic Pulmonary Fibrosis. Medicina (Kaunas). 2019;55(3):70. Published 2019 Mar 16. https://doi.org/10.3390/medicina55030070.

12. Amundson WH, Racila E, Allen T, et al. Acute exacerbation of interstitial lung disease after procedures. Respir Med. 2019;150:30-7. https://doi.org/10.1016/j.rmed.2019.02.012.

13. Kimura H, Ota H, Kimura Y, Takasawa S. Effects of Intermittent Hypoxia on Pulmonary Vascular and Systemic Diseases. Int J Environ Res Public Health. 2019;16(17):3101. Published 2019 Aug 26. https://doi.org/10.3390/ijerph16173101.

14. Chan MTV, Wang CY, Seet E, et al. Association of Unrecognized Obstructive Sleep Apnea With Postoperative Cardiovascular Events in Patients Undergoing Major Noncardiac Surgery. JAMA. 2019;321(18):1788-98. https://doi.org/10.1001/jama.2019.4783.

15. Senaratna CV, Perret JL, Lodge CJ, et al. Prevalence of obstructive sleep apnea in the general population: A systematic review. Sleep Med Rev. 2017;34:70-81. https://doi.org/10.1016/j.smrv. 2016.07.002.

16. Suen C, Ryan CM, Mubashir T, et al. Sleep Study and Oximetry Parameters for Predicting Postoperative Complications in Patients With OSA. Chest. 2019;155(4):855-67. https://doi.org/ 10.1016/j.chest.2018.09.030.

17. Nagappa M, Liao P, Wong J, et al. Validation of the STOP-Bang Questionnaire as a Screening Tool for Obstructive Sleep Apnea among Different Populations: A Systematic Review and MetaAnalysis. PLoS One. 2015;10(12):e0143697. Published 2015 Dec 14. https://doi.org/10.1371/journal.pone.0143697.

18. Chiu HY, Chen PY, Chuang LP, et al. Diagnostic accuracy of the Berlin questionnaire, STOP-BANG, STOP, and Epworth sleepiness scale in detecting obstructive sleep apnea: A bivariate meta-analysis. Sleep Med Rev. 2017;36:57-70. https://doi. org/10.1016/j.smrv.2016.10.004.

19. Dent E, Martin FC, Bergman H, Woo J, Romero-Ortuno R, Walston JD. Management of frailty: opportunities, challenges, and future directions. Lancet. 2019;394(10206):1376-86. https:// doi.org/10.1016/S0140-6736(19)31785-4.

20. Walston J, Buta B, Xue QL. Frailty Screening and Interventions: Considerations for Clinical Practice. Clin Geriatr Med. 2018;34(1):25-38. https://doi.org/10.1016/j.cger.2017.09.004.

21. Lin HS, Watts JN, Peel NM, Hubbard RE. Frailty and postoperative outcomes in older surgical patients: a systematic review. BMC Geriatr. 2016;16(1):157. Published 2016 Aug 31. https://doi.org/10.1186/s12877-016-0329-8.

22.• Khan M, Jehan F, Zeeshan M, et al. Failure to Rescue After Emergency General Surgery in Geriatric Patients: Does Frailty Matter?. J Surg Res. 2019;233:397-402. https://doi.org/10. $1016 /$ j.jss.2018.08.033. Very good clinical study evaluating aspects of failure to rescue in geriatric surgical patients. Demonstrates that frailty is an independent risk factor for fail to rescue.

23. Marengoni A, Vetrano DL, Manes-Gravina E, Bernabei R, Onder G, Palmer K. The Relationship Between COPD and Frailty: A Systematic Review and Meta-Analysis of Observational Studies. Chest. 2018;154(1):21-40. https://doi.org/10.1016/j.chest.2018. 02.014 .
24. Sheth JS, Xia M, Murray S, et al. Frailty and geriatric conditions in older patients with idiopathic pulmonary fibrosis. Respir Med. 2019;148:6-12. https://doi.org/10.1016/j.rmed.2019.01.008.

25. Shi T, Arnott A, Semogas I, et al. The Etiological Role of Common Respiratory Viruses in Acute Respiratory Infections in Older Adults: A Systematic Review and Meta-analysis. J Infect Dis. 2020;222(Supplement_7):S563-S569. https://doi.org/10. 1093/infdis/jiy662.

26. Drake T, Docherty AB, Harrison E, et al. Outcome of hospitalisation for COVID-19 in 330 patients with interstitial lung disease: an international multicentre study, medRxiv. 2020. https:// doi.org/10.1101/2020.07.15.20152967.

27. COVIDSurg Collaborative. Mortality and pulmonary complications in patients undergoing surgery with perioperative SARS-CoV-2 infection: an international cohort study [published correction appears in Lancet. 2020 Jun 9;:]. Lancet. 2020;396(10243):27-38. https://doi.org/10.1016/S01406736(20)31182-X.

28. Inzunza M, Romero C, Irarrázaval MJ, Ruiz-Esquide M, Achurra P, Quezada N, Crovari F, Muñoz R. Morbidity and Mortality in Patients with Perioperative COVID-19 Infection: Prospective Cohort in General, Gastroesophagic, Hepatobiliary, and Colorectal Surgery. World J Surg. 2021 Jun;45(6):1652-1662. https://doi.org/10.1007/s00268-021-06068-6. Epub 2021 Mar 21. PMID: 33748925; PMCID: PMC7982273.

29. Mazo V, Sabaté S, Canet J, et al. Prospective external validation of a predictive score for postoperative pulmonary complications. Anesthesiology. 2014;121(2):219-31. https://doi.org/10.1097/ ALN.0000000000000334.

30. Smetana GW. The Conundrum of Unnecessary Preoperative Testing. JAMA Intern Med. 2015;175(8):1359-61. https://doi. org/10.1001/jamainternmed.2015.2106.

31. Yokota S, Koizumi M, Togashi K, et al. Preoperative pulmonary function tests do not predict the development of pulmonary complications after elective major abdominal surgery: A prospective cohort study. Int J Surg. 2020;73:65-71. https://doi.org/10. 1016/j.ijsu.2019.11.032.

32. Oh TK, Park IS, Ji E, Na HS. Value of preoperative spirometry test in predicting postoperative pulmonary complications in high-risk patients after laparoscopic abdominal surgery. PLoS One. 2018;13(12):e0209347. Published 2018 Dec 19. https:// doi.org/10.1371/journal.pone.0209347.

33. Queiroz RS, Faria LMA, Carneiro JAO, Coqueiro RDS, Fernandes MH. Age and mini-mental state examination score can predict poor-quality spirometry in the elderly: a cross-sectional study. Clinics (Sao Paulo). 2018;73:e374. Published 2018 Oct 8. https:// doi.org/10.6061/clinics/2018/e374.

34. Cornelius ME, Wang TW, Jamal A, Loretan CG, Neff LJ. Tobacco Product Use Among Adults - United States, 2019. MMWR Morb Mortal Wkly Rep 2020;69:1736-1742. https:// doi.org/10.15585/mmwr.mm6946a4externalicon.

35. Cawkwell PB, Blaum C, Sherman SE. Pharmacological Smoking Cessation Therapies in Older Adults: A Review of the Evidence. Drugs Aging. 2015;32(6):443-51. https://doi.org/10. 1007/s40266-015-0274-9.

36. Janssen TL, Steyerberg EW, Langenberg JCM, et al. Multimodal prehabilitation to reduce the incidence of delirium and other adverse events in elderly patients undergoing elective major abdominal surgery: An uncontrolled before-and-after study. PLoS One. 2019;14(6):e0218152. Published 2019 Jun 13. https://doi.org/10.1371/journal.pone.0218152.

37. Kendall F, Oliveira J, Peleteiro B, Pinho P, Bastos PT. Inspiratory muscle training is effective to reduce postoperative pulmonary complications and length of hospital stay: a systematic review and meta-analysis. Disabil Rehabil. 2018;40(8):864-82. https://doi.org/10.1080/09638288.2016.1277396. 
38. Ge X, Wang W, Hou L, Yang K, Fa X. Inspiratory muscle training is associated with decreased postoperative pulmonary complications: Evidence from randomized trials. J Thorac Cardiovasc Surg. 2018;156(3):1290-1300.e5. https://doi.org/10.1016/j. jtcvs.2018.02.105.

39. Root CW, Beilin Y, McCormick PJ, Curatolo CJ, Katz D, Hyman JB. Differences in Outcomes After Anesthesia-Related Adverse Events in Older and Younger Patients. J Healthc Qual. 2020;42(4):195-204. https://doi.org/10.1097/JHQ.0000000000000216.

40. Hansen J, Rasmussen LS, Steinmetz J. Management of Ambulatory Anesthesia in Older Adults. Drugs Aging. 2020;37(12):86374. https://doi.org/10.1007/s40266-020-00803-9.

41. Spanjer MRK, Bakker NA, Absalom AR. Pharmacology in the elderly and newer anaesthesia drugs. Best Pract Res Clin Anaesthesiol. 2011;25(3):355-65. https://doi.org/10.1016/j.bpa.2011. 06.002 .

42. Lin C, Darling C, Tsui BCH. Practical Regional Anesthesia Guide for Elderly Patients. Drugs Aging. 2019;36(3):213-34. https://doi.org/10.1007/s40266-018-00631-y.

43. Aceto P, Incalzi RA, Bettelli G, et al. Perioperative Management of Elderly patients (PriME): recommendations from an Italian intersociety consensus [published correction appears in Aging Clin Exp Res. 2020 Sep 10;:]. Aging Clin Exp Res. 2020;32(9):1647-1673. https://doi.org/10.1007/ s40520-020-01624-X.

44. Desai V, Chan PH, Prentice HA, et al. Is Anesthesia Technique Associated With a Higher Risk of Mortality or Complications Within 90 Days of Surgery for Geriatric Patients With Hip Fractures? Clin Orthop Relat Res. 2018;476(6):1178-88. https://doi. org/10.1007/s11999.0000000000000147.

45. Balentine CJ, Meier J, Berger M, et al. Using Local Anesthesia for Inguinal Hernia Repair Reduces Complications in Older Patients. J Surg Res. 2021;258:64-72. https://doi.org/10.1016/j. jss.2020.08.054.

46. Hausman MS Jr, Jewell ES, Engoren M. Regional versus general anesthesia in surgical patients with chronic obstructive pulmonary disease: does avoiding general anesthesia reduce the risk of postoperative complications? Anesth Analg. 2015;120(6):140512. https://doi.org/10.1213/ANE.0000000000000574.

47. Young CC, Harris EM, Vacchiano C, et al. Lung-protective ventilation for the surgical patient: international expert panel-based consensus recommendations. Br J Anaesth. 2019;123(6):898913. https://doi.org/10.1016/j.bja.2019.08.017.

48. Ireland CJ, Chapman TM, Mathew SF, Herbison GP, Zacharias $\mathrm{M}$. Continuous positive airway pressure (CPAP) during the postoperative period for prevention of postoperative morbidity and mortality following major abdominal surgery. Cochrane Database Syst Rev. 2014;2014(8):CD008930. Published 2014 Aug 1. https://doi.org/10.1002/14651858.CD008930.pub2.
49. Barnett SR. Preoperative Assessment of Older Adults. Anesthesiol Clin. 2019;37(3):423-36. https://doi.org/10.1016/j.anclin. 2019.04.003.

50. Caglià P, Tracia A, Buffone A, et al. Physiopathology and clinical considerations of laparoscopic surgery in the elderly. Int $\mathbf{J}$ Surg. 2016;33(Suppl 1):S97-102. https://doi.org/10.1016/j.ijsu. 2016.05.044.

51. Kochi M, Hinoi T, Niitsu $\mathrm{H}$, et al. Risk factors for postoperative pneumonia in elderly patients with colorectal cancer: a sub-analysis of a large, multicenter, case-control study in Japan. Surg Today. 2018;48(8):756-64. https://doi.org/10.1007/s00595-018-1653-8.

52. Antoniou SA, Antoniou GA, Koch OO, Pointner R, Granderath FA. Laparoscopic colorectal surgery confers lower mortality in the elderly: a systematic review and meta-analysis of 66,483 patients. Surg Endosc. 2015;29(2):322-33. https://doi.org/10. 1007/s00464-014-3672-x.

53. Denny DL, Guido GW. Undertreatment of pain in older adults: an application of beneficence. Nurs Ethics. 2012;19(6):800-9. https://doi.org/10.1177/0969733012447015.

54. Sammons G, Ritchey W. Use of Transversus Abdominis Plane (TAP) Blocks for Pain Management in Elderly Surgical Patients. AORN J. 2015;102(5):493-7. https://doi.org/10.1016/j.aorn. 2015.09.003.

55. Pirrera B, Alagna V, Lucchi A, et al. Transversus abdominis plane (TAP) block versus thoracic epidural analgesia (TEA) in laparoscopic colon surgery in the ERAS program. Surg Endosc. 2018;32(1):376-82. https://doi.org/10.1007/s00464-017-5686-7.

56. Chang SC, Lai JI, Lu MC, et al. Reduction in the incidence of pneumonia in elderly patients after hip fracture surgery: An inpatient pulmonary rehabilitation program. Medicine (Baltimore). 2018;97(33): e11845. https://doi.org/10.1097/MD.0000000000011845.

57. Wang $\mathrm{TH}, \mathrm{Wu} \mathrm{CP}$, Wang LY. Chest physiotherapy with early mobilization may improve extubation outcome in critically ill patients in the intensive care units. Clin Respir J. 2018;12(11):2613-21. https://doi.org/10.1111/crj.12965.

58. Brocki BC, Andreasen JJ, Langer D, Souza DS, Westerdahl E. Postoperative inspiratory muscle training in addition to breathing exercises and early mobilization improves oxygenation in highrisk patients after lung cancer surgery: a randomized controlled trial. Eur J Cardiothorac Surg. 2016;49(5):1483-91. https://doi. org/10.1093/ejcts/ezv359.

59. Ball L, Almondo C, Pelosi P. Perioperative Lung Protection: General Mechanisms and Protective Approaches. Anesth Analg. 2020;131(6):1789-98. https://doi.org/10.1213/ANE. 0000000000005246 .

Publisher's Note Springer Nature remains neutral with regard to jurisdictional claims in published maps and institutional affiliations. 